\title{
ASSESSMENT OF THE IMPACT OF DEMAND SIDE MANAGEMENT ON DISTRIBUTION NETWORK VOLTAGE STABILITY
}

\author{
Document Version \\ Accepted author manuscript
}

Link to publication record in Manchester Research Explorer

Citation for published version (APA):

Tang, X., \& Milanovic, J. V. (2017). ASSESSMENT OF THE IMPACT OF DEMAND SIDE MANAGEMENT ON DISTRIBUTION NETWORK VOLTAGE STABILITY. In CIRED 2017

\section{Published in:}

CIRED 2017

\section{Citing this paper}

Please note that where the full-text provided on Manchester Research Explorer is the Author Accepted Manuscript or Proof version this may differ from the final Published version. If citing, it is advised that you check and use the publisher's definitive version.

\section{General rights}

Copyright and moral rights for the publications made accessible in the Research Explorer are retained by the authors and/or other copyright owners and it is a condition of accessing publications that users recognise and abide by the legal requirements associated with these rights.

\section{Takedown policy}

If you believe that this document breaches copyright please refer to the University of Manchester's Takedown Procedures [http://man.ac.uk/04Y6Bo] or contact uml.scholarlycommunications@manchester.ac.uk providing relevant details, so we can investigate your claim.

\section{OPEN ACCESS}




\section{ASSESSMENT OF THE IMPACT OF DEMAND SIDE MANAGEMENT ON DISTRIBUTION NETWORK VOLTAGE STABILITY}

\author{
Xiaoqing TANG \\ The University of Manchester - UK \\ xiaoqing.tang@manchester.ac.uk
}

\author{
Jovica V. MILANOVIĆ \\ The University of Manchester - UK \\ milanovic@manchester.ac.uk
}

\begin{abstract}
The prospect of electricity market liberalization, increasing renewable power penetration and network investment deferral has made demand side management (DSM) a key feature of future smart grid. This paper investigates the effect of DSM actions on voltage stability of distribution network. The analysis performed considers the effect that the load reduction, change in load recovery times and shifting of different type of load from one hour to the other can have on overall voltage stability of the network. A generic 295 bus distribution network is used to demonstrate this effect.
\end{abstract}

\section{INTRODUCTION}

Increasing customer load demand and renewable power penetration has brought many challenges to today's grids, e.g. system imbalance, renewable curtailment and network peak capacity issues. Demand side management (DSM) is a scheme that can help to tackle these challenges by encouraging end-users to reduce demand consumption during peak times or shift the energy use to desired times, e.g., when there is high renewable penetration, and such contribute to economic operation of power system, network investment deferral and system reliability enhancement [1-2]. Numerous business models for DSM activities, e.g., interruptible/direct control loads for system reliability enhancing service, increase/decrease loads together with energy storage devices for frequency regulation, change load shapes for wholesale price reduction and compensate for the intermittent renewables, have been extensively investigated in the literature and some of those have already been trialed in pilot sites by industries [2-5]. The trials include applications of DSM programmes for power system voltage stability enhancement in case of critical contingencies [6], using frequency responsive loads for grid frequency stability improvement [7], application of an event-driven emergency DSM scheme for power system security enhancement into the optimization problems to both keep a proper level of operational reserve and minimize the total cost [8], etc.

All existing models focus on various services that DSM can provide due to its flexibility or fast ramp provision. These DSM techniques focus mainly on improvement of normal operation or emergency response; however, to the best of authors' knowledge, there have been very few studies that analyze the impact of DSM during the load reconnection (recovery) interval (defined as the time when the load shed/shifted in the DSM schemes is reconnected). Furthermore, the impact of shifting different load composition in DSM activities on global grid voltage stability is not taken into account. For example, shifting large amount of induction motors (e.g., washing machines or air conditioning) from peak time to off-peak time, the load mix at both, peak and off-peak hours will be changed and hence the load response to network disturbances locally ( at buses where DSM was performed) and globally across the network. This may result in higher sensitivity of buses and the whole network to disturbances and potentially lead to unexpected network responses to disturbances and even to maloperation of protection system which would have been set based on historic network performance. Without proper analysis of the impact on power system performance, the action of DSM may endanger the system and lead to operation close to stability (voltage or angular or both) margin especially if there the disturbance happens right after DSM action.

To address these issues, this paper investigates the effect of DSM actions on overall voltage stability of distribution network at both the load reduction and recovery times and the extent that shifting of different type of load from one hour to the other can have on overall voltage stability of the network. A generic 295 bus distribution network is used to demonstrate this effect. Different types of load sectors (domestic, commercial, industrial) with corresponding mix of load categories (small and large induction motors, constant power, constant impedance and constant current load) in each of them are modelled in DigSILENT/PowerFactory based on typical structure and composition of demand in distribution network.

The paper demonstrates and quantify the impact of the DSM actions on distribution network performance at both the load reduction and load recovery time and establish the extent to which DSM can contribute, or otherwise, to overall voltage stability of the network.

\section{TEST SYSTEM MODELLING AND SIMULATION}

A 295-bus generic distribution network (GDN), as shown in Fig. 1, is used in the study. It comprises $275 \mathrm{kV}$ transmission in-feeds, $132 \mathrm{kV}$ and $33 \mathrm{kV}$ predominantly meshed sub-transmission networks, and $11 \mathrm{kV}$ predominantly radial distribution network. The network consists of 276 lines including overhead lines and underground cables, 37 transformers with various winding connections, 150 loads representing industrial, commercial and domestic loads, aggregated to $11 \mathrm{kV}$ (or above) distribution network. The locations of 
commercial, industrial and mixed-type load sectors are marked by different labels in Fig. 1. A composite load model with ZIP model and IM load is used for modelling each load in the test system [9-10], as shown in Fig. 2. Namely, the load at each bus is represented as a combination of constant impedance, current and power loads and IM loads, with assigned typical load structure and composition of demand in distribution network [11]. Each type of load classes (i.e. domestic, commercial, industrial and mixed-type) is assigned a daily profile as shown in Fig. 3, obtained from a real network in the U.K..

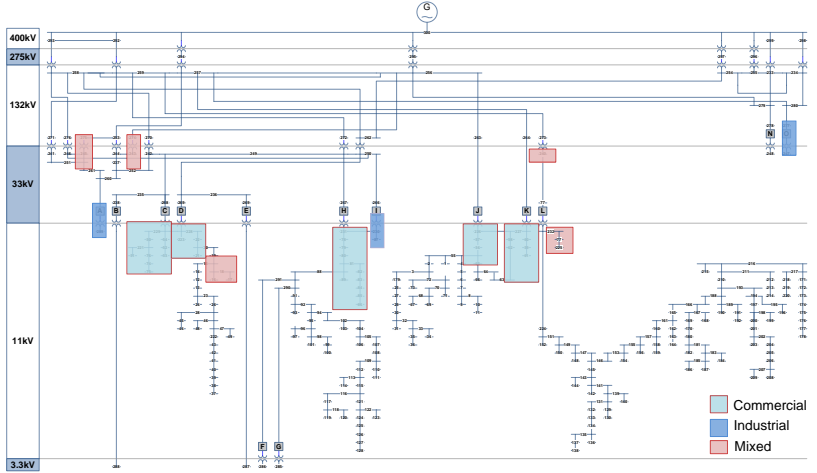

Fig. 1 Single line diagram of 295-bus generic distribution system $(\mathrm{GDN})$.

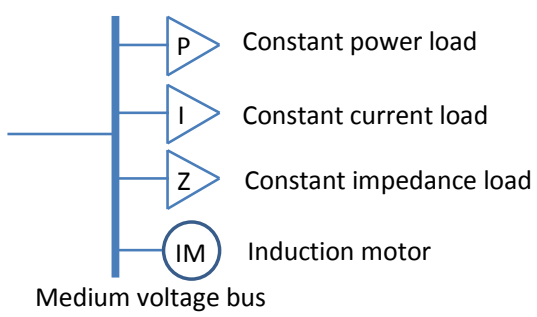

Fig. 2. Composite load model consisting of ZIP loads and an IM load.

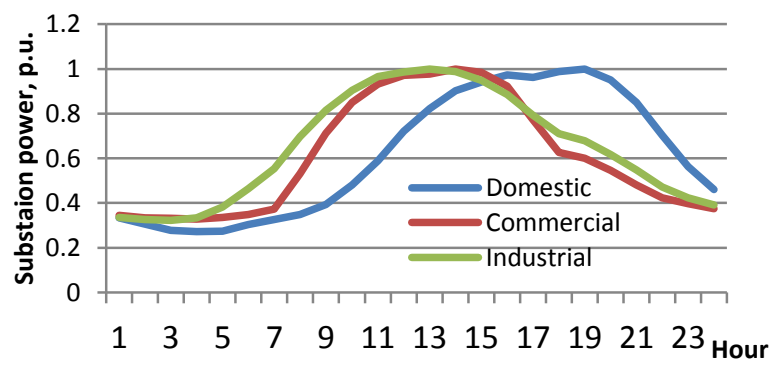

Fig. 3. Load profile for commercial, industrial and domestic substations.

\section{Simulating demand side management}

The typical DSM scheme, i.e., shifting load from peak time (referred to as load reduction period) to off-peak time (referred to as load recovery period) is investigated in this study. All simulations are carried out using commercial software - DIgSILENT/PowerFactory. The advantage of using the composite load model, as shown in Fig 2, when simulating demand shifting is that it allows the implementation of various types of analyses of the impact of the DSM actions on power system such as voltage and angular stability analysis.

Large industrial and commercial loads have long history in participation in DSM mechanism and have been used for this purpose in the past. In contrast, small and distributed residential loads are new in DSM market but have significant potential in supporting gird services due to their flexibilities. Therefore, the shifted load considered in the case study is the load from domestic load sectors. The typical loads that are shiftable from residential load sectors include constant impedance loads such as electric heating and night storage heating and induction motor loads (e.g. washing machine and dishwashers). Therefore, shifting different residential load type is investigated in the case study: (i) shifting IM loads; (ii) shifting constant impedance (Z) load; (iii) shifting IM and $\mathrm{Z}$ loads together. In total 8 different operating conditions including 6 demand shifting scenarios are considered in this study:

1) base case at peak time

2) shift domestic IM from peak time

3) shift domestic $Z$ from peak time

4) shift domestic IM $+Z$ from peak time

5) base case at low demand time

6) shift domestic IM to low time

7) shift domestic $Z$ to low time

8) shift domestic IM $+Z$ to low time

The simulation flow chart is given in Fig. 4. Voltage stability analysis is performed in DIgSILENT/PowerFactory at peak/low demand time (i.e. load reduction/recovery times) before and after shifting different load from domestic buses.

\section{VOLTAGE STABILITY ANALYSIS RESULTS}

PV curves are essential for analyzing the voltage stability of power systems. These curves are generated by increasing the power demand of selected loads or all loads (as the case of this report) and performing load flow to calculate the corresponding bus voltages until load flow calculation diverges. The power factors are kept constant for all buses during PV curve calculation. The bifurcation point is the critical point which represents the maximum loadability of the system and beyond this point the system is voltage ustable. The power transfer stability margin can be defined as the MW distance from the operating point to the critical point. 


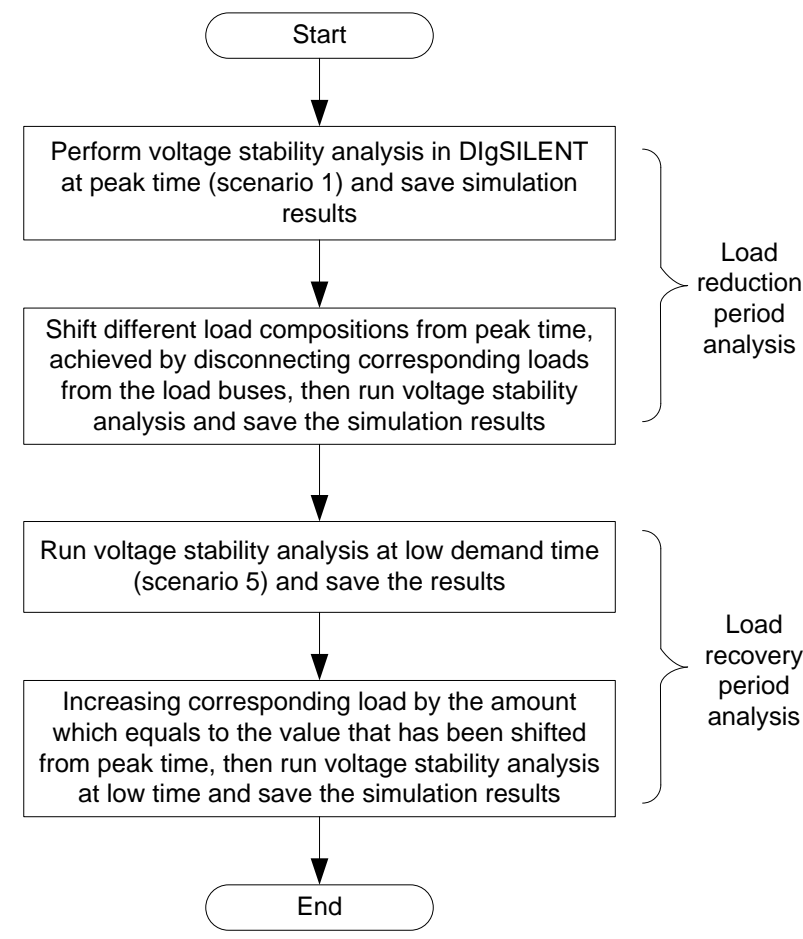

Fig. 4. Flow chart for simulating of DSM scheme- load shifting.

\section{Maximum Loadability}

The PV curves for shifting different load compositions for a typical bus from each load class (domestic, commercial, industrial and mixed loads) is presented in Fig. 5 for peak time and Fig. 6 for low times, respectively. The comparison between the base case (i.e before the load shifting action), as indicated by black curves, and the different DSM actions are analyzed. For load reduction time as shown in Fig. 5, it can be seen that shifting domestic induction motor (IM) load, as indicated by blue curves, the system maximum loadability has little change (1MW increase from $469.3 \mathrm{MW}$ of the base case to 470.3 for shifting IM load); Shifting domestic constant impedance $(Z)$ load and $\mathrm{IM}+Z$ loads, as indicated by green and pink curves, the system maximum loadability decreases more significantly compared with shifting IM loads, by 17.1 MW and 16.9 MW, respectively(maximum loadibality are 452.2 MW and 453.1MW). For load recovery time as shown in Fig. 6, shifting IM loads (blue and pink lines) to low demand time increases system maximum loadability at the low load time more significantly in contrast with shifting constant impedance load (green lines), 74.4 MW, 70.9 MW and 12.8MW, respectively. Therefore, it can be concluded that the network voltage stability changes with the DSM action and the extent to which DSM can affect depending on the type of load shifted (Induction motor (IM) load only, constant impedance load ( $\mathrm{Z}$ ) only, and IM and Z load) from one hour to the other.
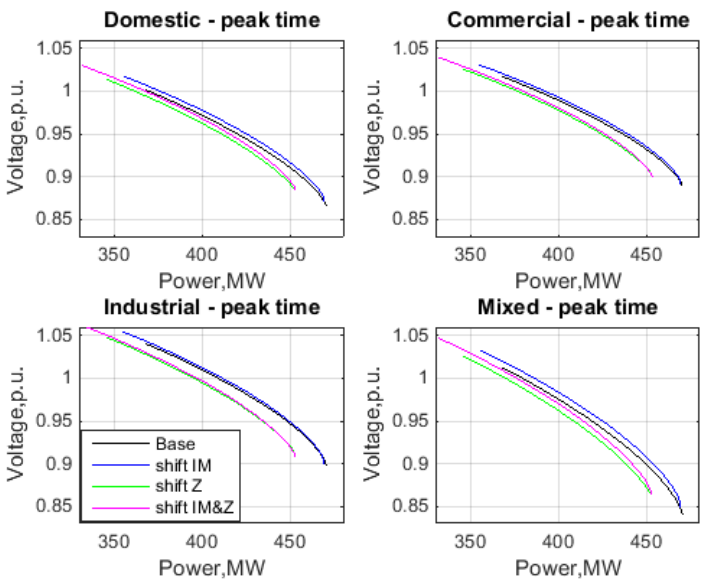

Fig. 5 PV curves for a typical bus at peak load time following the shift of different domestic load compositions from each load class (domestic, commercial industrial and mixed loads).
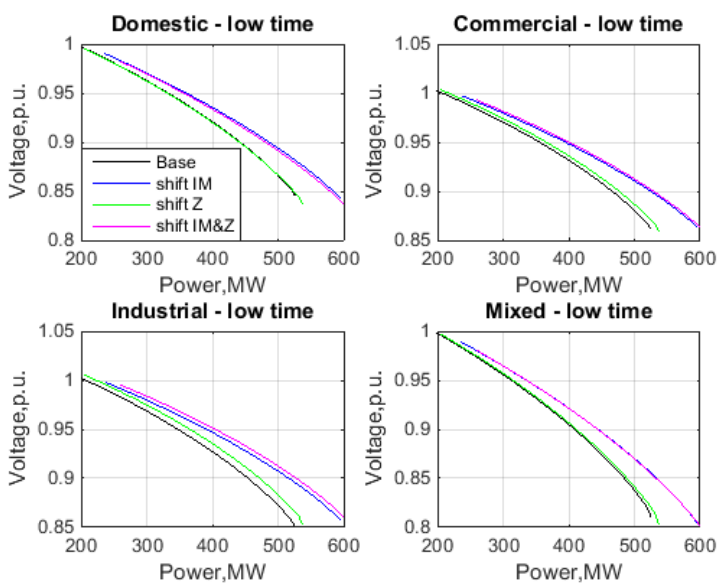

Fig. 6 PV curves for a typical bus at low load time following the shift of different domestic load compositions from each load class (domestic, commercial industrial and mixed loads)

Once voltage profiles from PV curve calculation for all buses of the 295-bus distribution network at peak and low demand times are obtained, the voltage changes for all 295 buses after shifting different load compositions are calculated and compared with the base case. Due to space limitation, only the results for low demand time and for shifting IM and $\mathrm{Z}$ loads are given in Fig 7 and 8 . The average of voltage changes compared with the base case, such as Fig 8, are calculated for each scenarios, and thus 6 average voltage change profiles are obtained and presented in Fig. 9 . For peak load time, as shown in the left figure in Fig. 9, it can be seen that at peak time at a given power demand value, e.g. 400MW, the overall system voltage level is lowered by shifting constant impedance loads as indicated by green and pink curves, while it is increased by shifting IM load. For low demand time, shifting IM loads (blue and pink lines) to low demand time increase the overall system voltage level more significantly compared with shifting constant 
impedance load (green line).
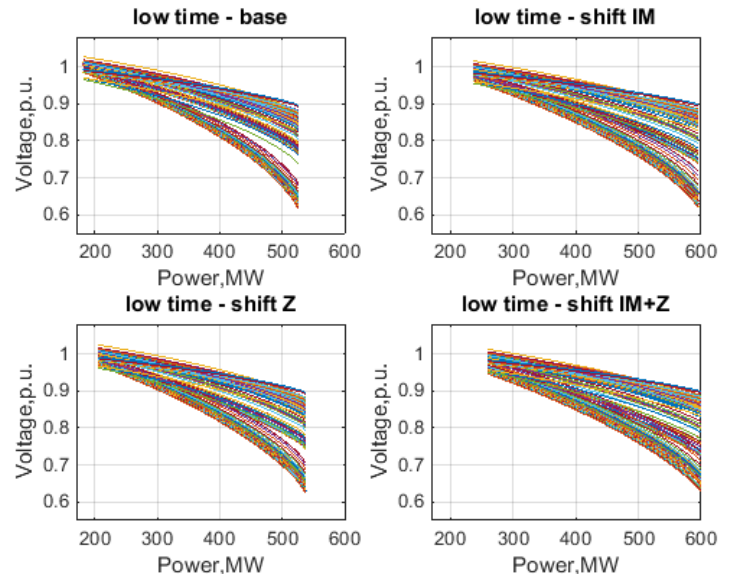

Fig.7 PV curves of all buses in 295 distribution network for shifting different domestic load compositions at low demand time (scenarios 5-8).
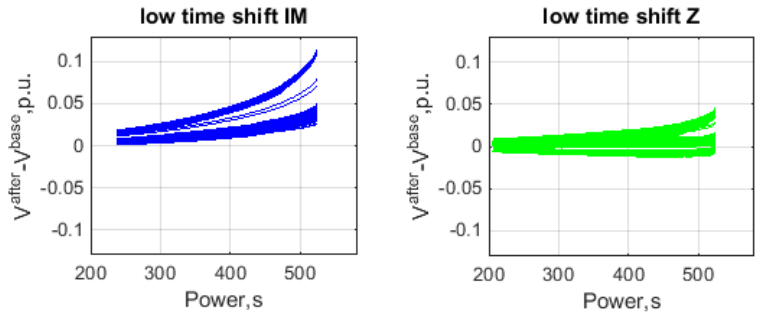

Fig. 8 Voltage profile changes at low demand time for shifting IM and shifting $\mathrm{Z}$ loads.
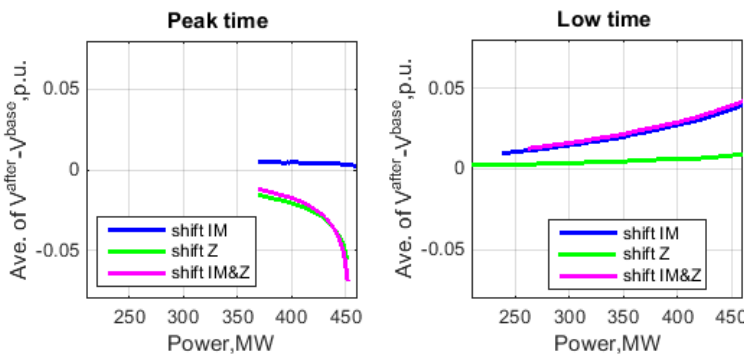

Fig. 9 Average of voltage changes at peak and low time for shifting 3 scenarios of domestic loads compared with the base case.

\section{SENSITIVITY ANALYSIS}

The sensitivity analysis of the PV curves is performed next. The ratio of voltage change over power change from the operating point $\left(\mathrm{V}_{0}, \mathrm{P}_{0}\right)$ to the critical point $\left(\mathrm{V}_{\mathrm{c} \text {., }}\right.$ $\mathrm{P}_{\mathrm{c}}$ ), given by (1), for both peak and low times, are calculated for all $11 \mathrm{kV}$ buses and presented in Fig 10 for shifting different domestic load (i.e, above 8 scenarios).

$$
\frac{\Delta V}{\Delta P}=\frac{V_{0}-V_{C}}{P_{0}-P_{c}}
$$

As shown in Fig. 10, the voltage sensitivity to power increase at peak time represented by the top 4 lines are higher than that at low demand time represented by the bottom 4 lines.

Heatmaps at peak and low times are generated for the distribution network according to the sensitivity analysis of PV curves (as shown in Fig. 10), and presented in Figs
11 and 12 , where 1 indicates $\max (\Delta \mathrm{V} / \Delta \mathrm{P})$ over all 295 buses $=0.0043$ p.u. $/ \mathrm{MW}$. It can be seen from Fig. 11 that the distribution network could be divided into 4 zones from left to right according the colour change. The most sensitive zone to power increase is the red area, i.e. zone 4 , which is the most stressed area in terms of voltage stability. Zone 4 consists mainly of domestic customers supplied through longest feeders in the studied network.

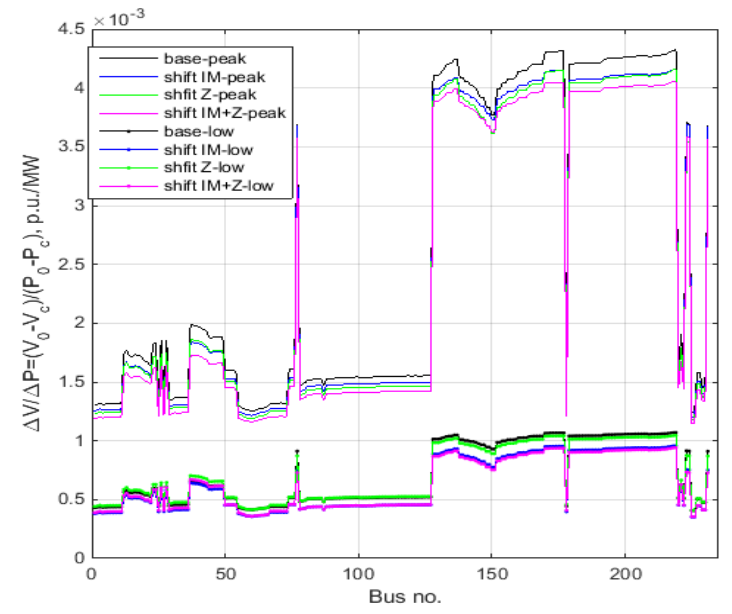

Fig. 10. The ratios $(\Delta \mathrm{V} / \Delta \mathrm{P})$ of voltage change over power change from the operating point $\left(\mathrm{V}_{0}\right)$ to the critical point $\left(\mathrm{V}_{\mathrm{c}}\right)$ for both peak (top 4 lines) and low times (bottom 4 lines) are calculated for all $11 \mathrm{kV}$ buses.

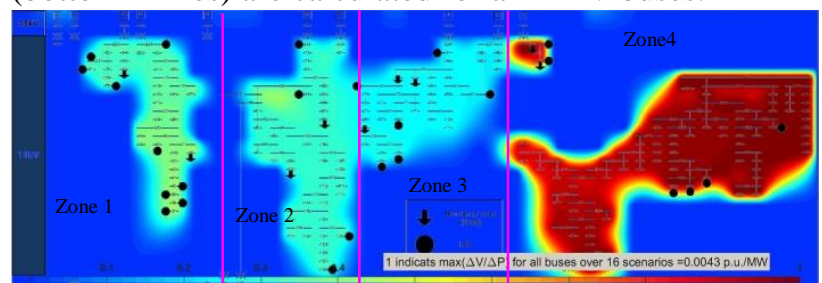

Fig. 11 heatmap for $\Delta \mathrm{V} / \Delta \mathrm{P}=\left(\mathrm{V}_{0}-\mathrm{V}_{\mathrm{c}}\right) /\left(\mathrm{P}_{\mathrm{o}}-\mathrm{P}_{\mathrm{c}}\right)$ from operating point to critical point at peak time for the base case.

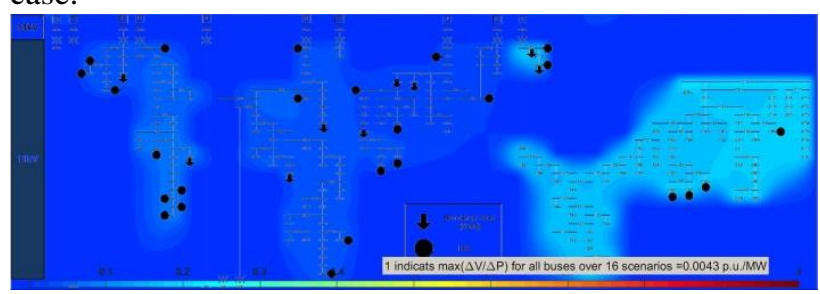

Fig. 12 heatmap for $\Delta \mathrm{V} / \Delta \mathrm{P}=\left(\mathrm{V}_{0}-\mathrm{V}_{\mathrm{c}}\right) /\left(\mathrm{P}_{\mathrm{o}}-\mathrm{P}_{\mathrm{c}}\right)$ from operating point to critical point at low time for the base case.

\section{CONCLUSIONS}

A generic 295 bus distribution network is used to demonstrate the effect of DSM actions on voltage stability of distribution network at both the load reduction and recovery times and the extent that shifting of different type of load from one hour to the other can have on overall voltage stability of the network. Different types of load sectors (domestic, commercial, industrial) with corresponding mix of load categories (small and 
large induction motors, constant power, constant impedance and constant current load) in each of them are modelled in DigSILENT/PowerFactory based on typical structure and composition of demand in distribution network. The summary of voltage stability analysis is:

(1) At load reduction time - shifting constant impedance (Z) loads at peak time decreases maximum loadability of the network more than shifting IM loads;

(2) At load recovery time - shifting IM loads to low time improves maximum loadability of the network more than shifting $\mathrm{Z}$ loads;

(3) Network sensitivity to voltage stability following DSM at peak time is higher than at low time, and zonal DSM participation should be identified first for effective network stress release.

It can be concluded that the network voltage stability changes with the DSM action and the extent to which DSM can affect it depends on the type of load shifted (Induction motor (IM) load only, constant impedance load (Z) only, and IM and Z load) from one hour to the other.

\section{REFERENCES}

[1] P. Palensky, and D. Dietmar, "Demand side management: Demand response, intelligent energy systems, ansd smart loads," IEEE Trans. Industrial Informatics, vol. 7, pp. 381-388, 2011.

[2] M. Behrangrad, "A review of demand side management business models in the electricity market," Renewable and Sustainable Energy Reviews, vol. 47, pp. 270-283, 2015.

[3] A.H. Mohsenian-Rad, V.W. Wong, J. Jatskevich, R. Schober and A. Leon-Garcia, "Autonomous demandside management based on game-theoretic energy consumption scheduling for the future smart grid," IEEE Trans. Smart Grid, vol. 1, pp. 320-331, 2010.

[4] I. Atzeni, L.G. Ordóñez, G. Scutari, D.P. Palomar and J.R. Fonollosa, "Demand-side management via distributed energy generation and storage optimization," IEEE Trans. Smart Grid, vol. 4, pp. 866-876, 2013.

[5] M. A. López, S. De La Torre, S. Martín and J.A. Aguado, "Demand-side management in smart grid operation considering electric vehicles load shifting and vehicle-to-grid support," International Journal of Electrical Power \& Energy Systems, vol. 64, pp. 689-698, 2015.

[6] C. M. Affonso, L. C. da Silva, F. G. Lima and S. Soares, "MW and MVar management on supply and demand side for meeting voltage stability margin criteria," IEEE Trans. Power Systems, vol. 19, pp. 1538-1545, 2004.

[7] J. A. Short, D. G. Infield and L. L. Freris, "Stabilization of grid frequency through dynamic demand control," IEEE Trans. power systems, vol. 22, pp. 1284-1293, 2007.

[8] Y. Wang, I. R. Pordanjani and W. Xu, "An eventdriven demand response scheme for power system security enhancement," IEEE Trans. Smart Grid, vol. 2, pp. 23-29, 2011.

[9] J. V. Milanović, J. Matevosiyan, A. Gaikwad, A. Borghetti, S. Ž. Djokić, Z. Dong, A. Halley, L. M. Korunović, S. M. Villanueva, J. Ma, P. Pourbeik, F. Resende, S. Sterpu, F. Villella, K. Yamashita, O. Auer, K. Karoui, D. Kosterev, S. K. Leung, D. Mtolo, S. M. Zali, A. Collin, Y. Xu, "CIGRE WG C4.605: Modelling and aggregation of loads in flexible power networks(566)", ISBN: 978-2-85873261-6, Feb. 2014.

[10] I. R. Navarro, "Dynamic load models for power systems," Ph.D. dissertation, Dept. Industrial Electrical Eng., Univ. Lund, Sweden, 2002.

[11]J.V.Milanović, Koji Yamashita, S. Martinez Villanueva, S.Ž.Djokić and L.M.Korunović, "International industry practice on power system load modelling", IEEE Trans. Power Systems, Vol. 28, No 3, pp. 3038-3046,2013 